\title{
Screening of Elderly for Chronic Kidney Disease
}

\author{
Višnja Ležaića, e,f Sanja Bajčetić ${ }^{b}$ Gordana Peruničić-Pekovićc Danica Bukvićd \\ Nada Dimkovićc, e, f Ljubica Djukanoviće \\ Department of Nephrology at a Clinical Center of Serbia, ${ }^{b}$ Zvezdara Clinical Center, ${ }^{\mathrm{C}}$ Zemun Clinical Center, \\ dSpecial Hospital for Endemic Nephropathy Lazarevac, ${ }^{e}$ Academy of Medical Science SMS, and \\ ${ }^{f}$ Medical Faculty, Belgrade University, Belgrade, Serbia
}

\section{Key Words}

Symptomless elderly $\cdot$ Kidney disease $\cdot$ Microalbuminuria

\begin{abstract}
Background and Aims: The frequency of chronic kidney disease (CKD) markers was assessed in two groups of patients over 60 years - one without and the other with hypertension. Methods: The cross-sectional study involved 585 asymptomatic elderly patients (227 males), 93 without and 492 with hypertension. Data on patients were obtained by interview, analysis of medical records and physical examinations. Serum and urine creatinine, proteinuria, microalbuminuria (MAU, turbidimetry), and urinary sediment were analyzed. Results: Among the 585 patients, there were $54.5 \%$ with a positive family history for hypertension and $14 \%$ for kidney diseases. MAU was significantly more frequent (30 vs. 11\%) and the mean estimated glomerular filtration rate (eGFR) higher $\left(71 \pm 14 \mathrm{vs} .64 \pm 14 \mathrm{ml} / \mathrm{min} / 1.73 \mathrm{~m}^{2}\right)$ in patients without hypertension than in those with hypertension. The majority of patients with stage 3 CKD had eGFR $>45 \mathrm{ml} /$ $\mathrm{min} / 1.73 \mathrm{~m}^{2}$ with normal urinary findings. Multivariate logistic regression analysis found age and treatment with angiotensin-converting enzyme inhibitors to be associated with reduced eGFR, MAU and proteinuria. In addition, smoking was associated with eGFR, but a family history for kidney disease and belonging to the group without hypertension were
\end{abstract}

associated with MAU. Conclusion: The high prevalence of markers for CKD in symptomless elderly without hypertension confirmed that the elderly, as a high-risk population, should be screened based on increased age alone.

Copyright $\odot 2012$ S. Karger AG, Basel

\section{Introduction}

Chronic kidney disease (CKD) is a worldwide public health problem with an increasing incidence and prevalence, poor outcome and high treatment costs. Due to its asymptomatic nature, CKD is frequently detected at an advanced stage, resulting in the loss of opportunities to influence its course and outcome. Progression of CKD to renal failure or other adverse outcomes can be prevented or delayed through early detection and treatment $[1,2]$. Currently, large efforts are being made for better detection of CKD. In 2002 the Kidney Disease Outcomes Quality Initiative (K/DOQI) of the National Kidney Foundation (NKF) developed a practice guideline for $\mathrm{CKD}$, recommending routine testing for detection of kidney disease during healthcare encounters for individuals at risk [3].

CKD disproportionately affects older persons. The incidence of end-stage renal disease increases with age and the majority of subjects who start renal replacement ther-

\section{KARGER \\ Fax +4161306 1234 \\ E-Mail karger@karger.ch}

www.karger.com
(C) 2012 S. Karger AG, Basel

$1420-4096 / 12 / 0356-0497 \$ 38.00 / 0$

Accessible online at:

www.karger.com/kbr
Prof. Dr. Višnja Ležaić

Department of Nephrology

Pasterova 2

RS-11000 Belgrade (Serbia)

E-Mail visnjalezaic@gmail.com 
apy are over 60 years of age $[4,5]$. Although there is a strong association between age and kidney function $[6$, 7], the clinical significance of reduced kidney function in older asymptomatic subjects remains disputable. In addition, it is unclear what portion of the decline in glomerular filtration rate (GFR) is due to higher prevalence of risk factors for kidney disease at older ages, such as hypertension, diabetes and vascular disease [8].

In the present study the frequency of markers for CKD was assessed in two groups of asymptomatic persons older than 60 years, one with hypertension and the other without hypertension. The aim of the study was to compare the frequency of markers for CKD in these two groups and find out whether older persons without hypertension had a sufficient prevalence of CKD markers to be screened, based on age alone.

\section{Patients and Methods}

\section{Patient Selection and Study Design}

This cross-sectional study involved 585 consecutive asymptomatic elderly patients ( 227 males; $68.97 \pm 6.24$ years, range 60 94) who presented for regular check-ups to their general practitioners in Belgrade Health Centers. Patients with previously known kidney and urinary tract diseases, diabetes, malignant disease, congestive heart disease, acute cardiovascular disturbances, systemic connective tissue disease, liver failure, acute infection or fever were not included in the study. The Ethics Committee of the Clinical Center of Serbia evaluated and approved this study, and patients gave their informed consents.

General practitioners carried out a survey of all patients that started with an interview in which the participants answered a detailed questionnaire on demographic issues, family and personal medical history with special attention to hypertension (duration, treatment) and data on smoking habits. From the medical records general practitioners also calculated mean systolic and diastolic blood pressure using all values of blood pressure registered in the previous year. After the interview all persons were examined physically including measurement of body weight, height and blood pressure. Arterial hypertension was defined as systolic blood pressure $\geq 140 \mathrm{~mm} \mathrm{Hg}$ and diastolic blood pressure $\geq 80 \mathrm{~mm} \mathrm{Hg}$ or if antihypertensive treatment was prescribed [9]. Smoking was defined as actual use of cigarettes (not ex-smokers).

Laboratory analyses involved serum and urine creatinine measurement by a kinetic Jaffé method, the urine dipstick test for proteinuria, determination of urine albumin using a turbidimetric method and urinary sediment analysis in the random spot urine specimen. Proteinuria was defined when the dipstick analysis quantified protein as $1+$ or more. The urinary albumin/creatinine ratio was used for estimation of total daily albumin excretion [10]. A urinary albumin to urinary creatinine ratio $\geq 25 \mathrm{mg} / \mathrm{g}$ creatinine for women and $\geq 17 \mathrm{mg} / \mathrm{g}$ creatinine for men defined microalbuminuria (MAU) [11]. Urinary sediment was examined under a microscope and $<5$ red or white blood cells per high- power field were considered normal. All analyses were done in the same laboratory (Institute for Laboratory Medicine Hexalab, Belgrade, Serbia).

Estimated GFR (eGFR) was estimated using the abbreviated MDRD study equation:

$$
\operatorname{eGFR}\left(\mathrm{ml} / \mathrm{min} / 1.73 \mathrm{~m}^{2}\right)=186 \times(\mathrm{Scr})^{-1.154} \times(\text { Age })^{-0.203} \times
$$

(0.742 if female).

Based on the presence of MAU and/or proteinuria and eGFR MDRD values, patients were classified into stages in accordance with the CKD classification of the NFK [3]: stage 1 (eGFR $>90 \mathrm{ml} /$ $\mathrm{min} / 1.73 \mathrm{~m}^{2}$ ) and stage 2 (eGFR $\left.60-89 \mathrm{ml} / \mathrm{min} / 1.73 \mathrm{~m}^{2}\right)$ were defined as renal damage characterized by the presence of MAU and/ or proteinuria in addition to the equated eGFR values; stage 3 eGFR $30-59 \mathrm{ml} / \mathrm{min} / 1.73 \mathrm{~m}^{2}$; stage 4 - eGFR $15-30 \mathrm{ml} / \mathrm{min} /$ $1.73 \mathrm{~m}^{2}$, and stage $5-\mathrm{eGFR}<15 \mathrm{ml} / \mathrm{min} / 1.73 \mathrm{~m}^{2}$. In addition, stage 3 CKD was divided into two sub-stages: sub-stage 3a with a GFR of $45-59 \mathrm{ml} / \mathrm{min} / 1.73 \mathrm{~m}^{2}$ and sub-stage $3 \mathrm{~b}$ with a GFR of $30-44 \mathrm{ml} / \mathrm{min} / 1.73 \mathrm{~m}^{2}[12,13]$.

The results were expressed as mean values with standard deviations (mean $\pm \mathrm{SD}$ ). The significance of differences between mean values for groups was calculated using the Mann-Whitney $\mathrm{U}$ test and Student's $\mathrm{t}$ test. $\chi^{2}$ or Fisher's test was used to compare frequency. The impact of covariates on the markers of CKD was tested by univariate/multivariate logistic regression analysis. Only those covariates found significant at the 0.1 level by univariate analysis were used in multivariate analysis. The analysis was used to assess the association of the dichotomous dependent variables proteinuria (1+ or more assessed by urine dipstick test), MAU (urinary albumin to creatinine ratio $\geq 25 \mathrm{mg} / \mathrm{g}$ creatinine for women and $\geq 17 \mathrm{mg} / \mathrm{g}$ creatinine for men) and eGFR $(<60 \mathrm{ml} /$ $\mathrm{min} / 1.73 \mathrm{~m}^{2}$ ) with the following independent variables: age, gender, hypertension, BMI, smoking habit, positive family history for kidney disease and hypertension, actual systolic and diastolic blood pressure and angiotensin-converting enzyme inhibitor (ACEi) treatment. Analyses were adjusted for potential confounding factors. $\mathrm{p}<0.05$ was considered significant. All analyses were performed using the SPSS statistical software package (Version 10; SPSS).

\section{Results}

Data on the studied patients are presented in table 1. According to average systolic and diastolic blood pressure in the previous year the patients were divided into two groups: 492 patients with hypertension and 93 patients without hypertension. None of the patients without hypertension were treated with ACEi, while $69.7 \%$ of patients with hypertension were treated with ACEi. No significant differences in age and sex were found between normotensive and hypertensive patients. Although mean values for BMI indicated that overweight was common in both groups, normotensive patients had a significantly lower BMI, while $10.4 \%$ of normotensive but $18.5 \%$ of hypertensive patients were obese (BMI $>30)$. According to 
the proportion of patients undergoing regular urine and laboratory checks in the year preceding the study, it was obvious that most subjects were under medical control. $82(14 \%)$ patients had a positive family history for kidney diseases and 319 (54.5\%) for hypertension, mostly patients actually with hypertension.

The results of laboratory analyses are also presented in table 1. Mean serum creatinine levels were normal in males and females of both groups but the normotensive group had significantly lower values than the hypertensive group. In addition, $10(10.8 \%)$ normotensive patients and $112(22.8 \%)$ hypertensive patients exhibited serum creatinine concentrations above the upper normal limit $\left(\chi^{2}=4.211, \mathrm{p}=0.040\right)$. Mean eGFR was $>60 \mathrm{ml} / \mathrm{min} /$ $1.73 \mathrm{~m}^{2}$ in both groups but significantly higher in normotensive patients. The prevalence of patients in stage 2 tended to be higher in normotensive than in hypertensive patients but not significantly, while the prevalence of patients in stage $3 \mathrm{CKD}$ was significantly higher in hypertensive than in normotensive patients $\left(\chi^{2}=4.183, \mathrm{p}=\right.$ $0.04)$. MAU was found in $82(14.0 \%)$ patients, significantly more frequently in the normotensive group $\left(\chi^{2}=\right.$ $14.923, \mathrm{p}=0.0001)$. Proteinuria and erythrocyturia were similarly prevalent in both groups.

The frequency of all examined markers for kidney disease is presented separately for normotensive and hypertensive patients in figure $1 \mathrm{a}$ and $\mathrm{b}$. eGFR $>60 \mathrm{ml} /$ $\mathrm{min} / 1.73 \mathrm{~m}^{2}$ with normal urinary findings occurred at a similar rate in patients from both groups (50 vs. $53 \%$ ). Although fewer normotensive patients had eGFR $<60 \mathrm{ml} /$ $\mathrm{min} / 1.73 \mathrm{~m}^{2}$ with normal urinary findings than hypertensive subjects (16 vs. $31 \%$ ), the difference was not significant. The remaining patients had a combination of abnormalities. In comparison to hypertensive patients, more normotensive patients had normal eGFR with proteinuria and/or MAU (24 vs. 5\%), and the difference was significant $\left(\chi^{2}=31.561, p=0.0001\right)$. No significant difference was found in the frequency of other combinations of abnormalities between the two patient groups. Taken together, 307 of our patients (52.5\%) had normal laboratory findings, while the remaining $47.5 \%$ had at least one marker for kidney disease.

Patients in stage 3 of CKD were subdivided into stage $3 a$ with eGFR between 45 and $59.9 \mathrm{ml} / \mathrm{min} / 1.73 \mathrm{~m}^{2}$ and stage $3 \mathrm{~b}$ with eGFR between 30 and $44.9 \mathrm{ml} / \mathrm{min} / 1.73 \mathrm{~m}^{2}$ (table 1). Urine analysis in these subgroups of patients showed that 11 out of 20 (55.0\%) normotensive and 127 out of 185 (68.4\%) hypertensive patients in subgroup 3a had normal urinary findings and the difference was not significant. Values were found to be similar for subgroup
Table 1. Data on patients obtained by questionnaire, medical record analysis, objective examination and laboratory analysis

\begin{tabular}{lcc}
\hline & $\begin{array}{l}\text { Patients without } \\
\text { hypertension } \\
(\mathrm{n}=93)\end{array}$ & $\begin{array}{l}\text { Patients with } \\
\text { hypertension } \\
(\mathrm{n}=492)\end{array}$ \\
\hline Mean age $\pm \mathrm{SD}$, years & $69.6 \pm 5.8$ & $68.8 \pm 6.3$ \\
Range & $60-84$ & $60-94$ \\
$>70$ years $(>80$ years $), \mathrm{n}$ & $46(3)$ & $209(25)$ \\
\hline Males, $\mathrm{n}(\%)$ & $39(41.9)$ & $188(38.2)$ \\
Mean BMI $\pm \mathrm{SD}$ & $25.43 \pm 5.2^{\mathrm{a}}$ & $27.26 \pm 5.4$ \\
$\mathrm{BMI} \geq 30 \mathrm{~kg} / \mathrm{m}^{2}$ & $9(10.4)$ & $91(18.5)$ \\
\hline
\end{tabular}

Mean blood pressure $\pm \mathrm{SD}, \mathrm{mm} \mathrm{Hg}$

$\begin{array}{lcc}\text { Systolic } & 125.28 \pm 10.11^{\mathrm{b}} & 139.38 \pm 17.8 \\ \text { Range } & 105-155 & 100-210 \\ \text { Diastolic } & 78.36 \pm 6.32^{\mathrm{b}} & 84.36 \pm 9.8 \\ \text { Range } & 70-100 & 60-125 \\ \text { Systolic in previous year } & 128.11 \pm 10.53^{\mathrm{b}} & 143.77 \pm 13.4 \\ \text { Diastolic in previous year } & 79.86 \pm 5.98^{\mathrm{b}} & 85.0 \pm 8.1 \\ \text { Hypertension duration, years } & 0 & 12.02 \pm 7.6 \\ \text { ACEi therapy, n (\%) } & 0 & 343(69.7)\end{array}$

\begin{tabular}{llr}
\hline Positive family history for & & \\
$\quad$ Kidney disease, $\mathrm{n}(\%)$ & $23(24.7)$ & $59(12.1)$ \\
$\quad$ Hypertension, $\mathrm{n}(\%)$ & $17(18.3)$ & $302(61.4)$ \\
\hline Smoking habits, n (\%) & $17(18.3)$ & $54(10.9)$
\end{tabular}

\begin{tabular}{llc}
\hline Previous checking, $\mathrm{n}(\%)$ & & \\
$\quad$ Urine & $65(69.8)$ & $366(74.4)$ \\
$\quad$ Serum creatinine & $57(61.3)$ & $324(65.8)$ \\
\hline Mean sCr $\pm \mathrm{SD}, \mu \mathrm{mol} / \mathrm{l}$ & $85.33 \pm 15.49^{\mathrm{c}}$ & $93.77 \pm 22.74$ \\
Male & $95.28 \pm 15.2^{\mathrm{d}}$ & $106.44 \pm 25.8$ \\
Female & $78.18 \pm 11.3^{\mathrm{e}}$ & $86.21 \pm 16.6$
\end{tabular}

\begin{tabular}{lll}
\hline $\begin{array}{l}\text { Mean eGFR MDRD } \pm \mathrm{SD}, \\
\mathrm{ml} / \mathrm{min} / 1.73 \mathrm{~m}^{2}\end{array}$ & $70.54 \pm 14.40^{\mathrm{b}}$ & $63.73 \pm 14.17$ \\
$<60 \mathrm{ml} / \mathrm{min} / 1.73 \mathrm{~m}^{2}, \mathrm{n}(\%)$ & $6(15.4)$ & $74(39.3)$ \\
$\quad$ Male & $14(25.9)$ & $114(37.5)$ \\
$\quad$ Female & $6(6.4)$ & $21(4.7)$ \\
\hline CKD stage, $\mathrm{ml} / \mathrm{min} / 1.73 \mathrm{~m}^{2}, \mathrm{n}(\%)$ & $283(57.5)$ \\
1 eGFR $\geq 90$ & $67(72.0)$ & $143(29.0)$ \\
2 eGFR $60-89.9$ & $17(18.3)^{\mathrm{f}}$ & $42(8.5)$ \\
3a eGFR $45-59.9$ & $3(3.2)$ & $3(0.6)$ \\
3b eGFR $30-44.9$ & 0 & $23.53 \pm 118.5$ \\
4 eGFR $15-29.9$ & $27.35 \pm 36.1$ & $(5.79)$ \\
\hline Mean MAU $\pm \mathrm{SD}, \mathrm{mg} / \mathrm{g}$ uCr & $(3.85)$ & 24 \\
Patients, $\mathrm{n}(\%)$ with & $10^{\mathrm{b}}$ & 30 \\
$\quad>17 \mathrm{mg} / \mathrm{g} \mathrm{uCr}$ for males & $18^{\mathrm{b}}$ & $79(16.0)$ \\
$\quad>25 \mathrm{mg} / \mathrm{g} \mathrm{uCr}$ for females & $9(9.6)$ & $30(6.1)$ \\
\hline Proteinuria $(\geq+1)$ & $7(7.5)$ & \\
\hline Erythrocyturia $(\geq+1)$ & &
\end{tabular}

$\mathrm{sCr}=$ serum creatinine concentration; $\mathrm{CKD}=$ chronic kidney disease; $\mathrm{MAU}=$ microalbuminuria.

${ }^{\mathrm{a}} \mathrm{p}=0.004 ;{ }^{\mathrm{b}} \mathrm{p}=0.0001 ;{ }^{\mathrm{c}} \mathrm{p}=0.012 ;{ }^{\mathrm{d}} \mathrm{p}=0.05,{ }^{\mathrm{e}} \mathrm{p}=0.017 ;{ }^{\mathrm{f}}$ both $3 a+3 b$ CKD: $\chi^{2}=4.183, p=0.04$. 

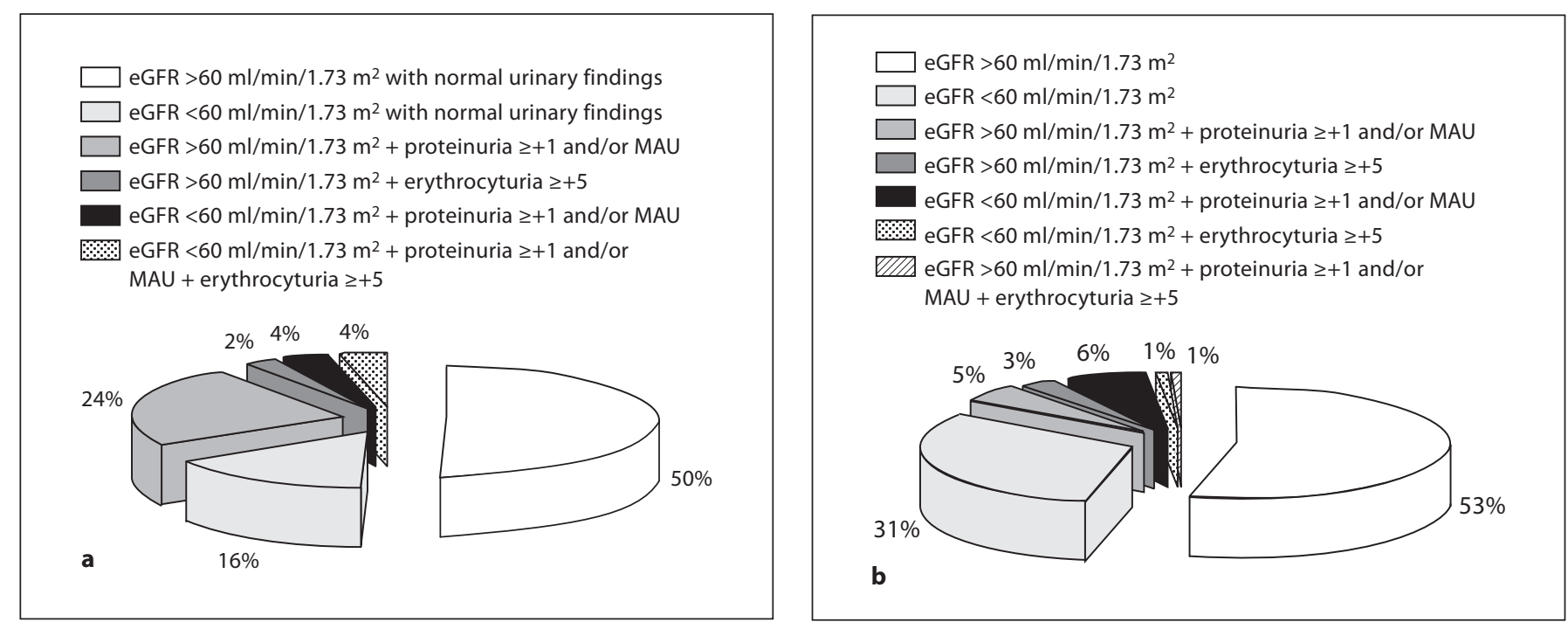

Fig. 1. Frequency of all examined markers for kidney disease for normotensive (a) and hypertensive (b) patients.

Table 2. Variables associated with eGFR, MAU and proteinuria as dichotomous dependent variables determined by univariate/multivariate logistic regression analysis

\begin{tabular}{lrll}
\hline Variable & \multicolumn{1}{l}{$\mathrm{B}$} & $\mathrm{p}$ & $95 \% \mathrm{CI}$ \\
\hline eGFR & & & \\
$\quad$ Age & 0.091 & 0.000 & $1.095(1.053 ; 1.139)$ \\
$\quad$ Smoking & -0.823 & 0.029 & $0.439(0.210 ; 0.917)$ \\
$\quad$ ACEi & 1.035 & 0.003 & $2.815(1.431 ; 5.540)$ \\
$\quad$ Constant & -7.804 & 0.000 & \\
MAU & & & \\
$\quad$ ACEi & 0.934 & 0.021 & $2.283(1.120 ; 4.832)$ \\
Family history for & & & \\
$\quad$ kidney disease & 1.136 & 0.006 & $3.116(1.378 ; 7.045)$ \\
$\quad$ Group & -1.463 & 0.000 & $0.232(0.113 ; 0.475)$ \\
$\quad$ Constant & 0.228 & 0.748 & \\
Proteinuria & & & \\
$\quad$ Age & 0.054 & 0.016 & $1.056(1.010 ; 1.103)$ \\
$\quad$ ACEi & 0.697 & 0.055 & $2.008(0.984 ; 4.097)$ \\
$\quad$ Constant & -6.082 & 0.000 & \\
\hline
\end{tabular}

3b: 2 (10\%) normotensive and 26 (14.3\%) hypertensive patients had normal urinary findings. A significant difference was only found in the frequency of proteinuria with erythrocyturia between patients without hypertension $(3 / 20)$ and those with hypertension (1/185) in subgroup $3 a$ (Fisher's test $p=0.0044$ ), while the frequency in MAU and/or proteinuria as well as in isolated erythrocyturia differed insignificantly between the subgroups.
Variables associated with proteinuria, MAU and eGFR as dichotomous dependent variables were determined by univariate/multivariate logistic regression analysis (table 2). The results showed that eGFR $<60 \mathrm{ml} / \mathrm{min} / 1.73 \mathrm{~m}^{2}$ was associated with older age (positive relationship), smoking (negative relationship), and ACEI treatment. MAU was associated with ACEi treatment (positive relationship) in addition to the family history for kidney disease (positive relationship) and belonging to the group without hypertension. Age and ACEi treatment were found as variables significantly associated with proteinuria.

\section{Discussion}

In the present study the prevalence of markers for CKD was determined in two groups of persons older than 60 years - one without hypertension and the other with hypertension. The patients were asymptomatic for kidney disease. Although fewer persons without hypertension had eGFR $<60 \mathrm{ml} / \mathrm{min} / 1.73 \mathrm{~m}^{2}$ with normal urinary findings than those with hypertension, the difference was not significant. However, a significantly higher percent of normotensive patients had proteinuria and/or MAU in comparison with hypertensive ones. Taken together, 46 (50\%) persons without hypertension and 231 (47\%) with hypertension had at least one marker for kidney disease and the difference was not significant. This prevalence 
was higher from the one found in the general population $[5,14]$ but similar to values reported in studies involving the elderly. Thus, in the PROSPER study that included 5,804 subjects between the ages of 70 and 82 years from Scotland, Ireland and the Netherlands, 53.3\% had GFR $<60 \mathrm{ml} / \mathrm{min} / 1.73 \mathrm{~m}^{2}$ [15]. The prevalence of CKD in persons $\geq 65$ years was approximately $44 \%$ in both KEEP and NHANES participants [16].

A high prevalence of CKD in elderly persons is not only partly due to the well-known decline of GFR during normal aging [7], but also to multiple risk factors appearing in the elderly that contribute to its development. The selection criteria for the present study allowed inclusion of persons above 60 years without comorbidities that could influence kidney function, except hypertension. Nevertheless, analysis of the data obtained by the questionnaire showed that older age and hypertension were not the only risk factors for CKD in the examined group. A positive family history for kidney disease, smoking and obesity were present with similar frequency in persons without and with hypertension. Therefore, the difference in the prevalence of CKD markers in the two groups could not be explained by the difference in the prevalence of these risk factors. The main difference between the groups was the presence or absence of hypertension, a well-known risk factor for CKD. Comparison of prevalence of CKD markers in elderly persons without hypertension and those with hypertension enabled us to find out whether older age alone was associated with a significant prevalence of CKD markers. Normotensive patients had a significantly lower mean serum creatinine level and a significantly higher mean eGFR. In this group, eGFR $<60 \mathrm{ml} / \mathrm{min} / 1.73 \mathrm{~m}^{2}$ was found in $20(22 \%)$ persons, while in the group with hypertension it occurred in 188 $(38 \%)$ persons $\left(\chi^{2}=4.183, p=0.04\right)$. However, when eGFR and urinary findings were considered together, prevalence of eGFR $<60 \mathrm{ml} / \mathrm{min} / 1.73 \mathrm{~m}^{2}$ with normal urinary findings differed insignificantly between persons without and with hypertension.

Moreover, MAU was found significantly more frequently in normotensive (28-30\%) than in hypertensive $(54-11 \%)$ patients $\left(\chi^{2}=14.923, \mathrm{p}=0.0001\right)$. A higher prevalence of MAU was found in normotensive patients with GFR $>60$ and $<60 \mathrm{ml} / \mathrm{min} / 1.73 \mathrm{~m}^{2}$ when compared with hypertensive ones. Also, the prevalence of MAU and/or proteinuria was significantly higher in patients without hypertension than in those with hypertension [37 (40\%) vs. $\left.114(23 \%) ; \chi^{2}=5.535, p=0.018\right]$. Although we cannot offer a complete explanation for these differences, one factor that contributes to the lower prevalence of protein-

Screening of Elderly for Chronic Kidney

Disease uria in patients with hypertension might be the use of ACEi by $70 \%$ of the patients with hypertension, but none of the patients without hypertension. This is supported by the results of multivariate logistic regression that found the treatment with ACEi as a significant independent variable associated with MAU and proteinuria. In addition, hypertension was already known and treated before the screening study in all but 5 patients. It could be proposed that because hypertension was treated in almost all patients, blood pressure did not appear as a significant predictor either for eGFR or for MAU. Age was found to be significantly associated with reduced eGFR and proteinuria, but positive family history for kidney disease and belonging to the group without hypertension were associated with MAU. All these data obtained by logistic regression analysis as well as the high prevalence of MAU and proteinuria in persons over 60 years without hypertension showed that older age is significantly associated with kidney damage.

MAU and/or proteinuria are considered important markers for diagnosis, not only for stages 1 and 2 but also for stage $3 \mathrm{CKD}$. According to the classification of CKD in the NKF/DOQI clinical practice guidelines, stages 1 and 2 are defined by the presence of signs of kidney damage (albuminuria, erythrocyturia or abnormalities on renal ultrasound) but only impaired eGFR was necessary to classify someone with stage 3-5 CKD [11]. As eGFR declines with age, many elderly, especially women, have eGFR $<60 \mathrm{ml} / \mathrm{min} / 1.73 \mathrm{~m}^{2}$. Therefore, if age and gender influences on eGFR are not taken into account, many persons with eGFR between 30 and $59 \mathrm{ml} / \mathrm{min} / 1.73 \mathrm{~m}^{2}$ will be falsely identified as patients with renal disease [12, 13]. Therefore, several authors proposed redefinition of stage $3 \mathrm{CKD}$ to improve both the diagnostic and prognostic value of the classification $[17,18]$. Recently, the clinical guidelines of the National Institute for Clinical Excellence (United Kingdom) suggested subdividing stage 3 CKD into no less than four subcategories, based on whether the eGFR is $<45 \mathrm{or}>45 \mathrm{ml} / \mathrm{min} / 1.73 \mathrm{~m}^{2}$ and the presence or absence of proteinuria [13]. Using this recommendation, we divided stage $3 \mathrm{CKD}$ into two according to eGFR: stage 3a with eGFR between 45 and $59.9 \mathrm{ml} /$ $\mathrm{min} / 1.73 \mathrm{~m}^{2}$ and stage $3 \mathrm{~b}$ with eGFR between 30 and 44.9 $\mathrm{ml} / \mathrm{min} / 1.73 \mathrm{~m}^{2}$, and analyzed the prevalence of proteinuria in these sub-stages. Most patients with eGFR $<60$ $\mathrm{ml} / \mathrm{min} / 1.73 \mathrm{~m}^{2}$ belonged to stage $3 \mathrm{a}$ with normal urinary findings and that was found in both normotensive and hypertensive patients. Although some other authors also found that eGFR $<45 \mathrm{ml} / \mathrm{min} / 1.73 \mathrm{~m}^{2}$ was much less common in older persons [19], the proposal for changes 
of current KDIGO guidelines suggests splitting stage 3 into $\mathrm{A}$ and $\mathrm{B}$ and modification of stages by including different degrees of proteinuria [20]. Nevertheless, a reduction of eGFR $<60 \mathrm{ml} / \mathrm{min} / 1.73 \mathrm{~m}^{2}$ was shown to be an independent risk factor for total and cardiovascular mortality $[17,19,21,22]$. Therefore, older persons with eGFR $<60 \mathrm{ml} / \mathrm{min} / 1.73 \mathrm{~m}^{2}$ should be treated and followed carefully regardless of the well-known decline of eGFR with age.

A diagnosis of CKD stage 3 or worse requires the presence of reduced kidney function to be documented over at least 3 months [23]. As our study was a cross-sectional one, we decided to present the prevalence of particular markers of CKD (eGFR, MAU, proteinuria, erythrocyturia) but not the prevalence of $\mathrm{CKD}$, although many epidemiological studies use the term CKD for reduced eGFR with proteinuria detected at a single time point $[19,24$, 25]. Although erythrocyturia is frequently the sign of urological disease, in the patients examined it most frequently appeared with MAU/proteinuria that indicated kidney damage. All patients with any detected urinary marker as well as those with eGFR $<60 \mathrm{ml} / \mathrm{min} / 1.73 \mathrm{~m}^{2}$ were advised to continue examination by their family doctor. Clinical validation of eGFR to screen elderly for $\mathrm{CKD}$ is recommended whenever a serum creatinine is obtained. It would be of particular importance when prescribing a drug to this population which might cause progression due to drug-drug interactions or serious adverse effects. Although it is not a subject of the present study, the tendency of CKD stage 3 to progress to renal failure is less than estimated from studies of selected patient groups, and that high mortality forestalls the development of renal failure in many patients [26]. These facts entail cost-effectiveness, which can be alluded to as an area for future study.

Our study has some limitations. The subjects involved were selected from the population of patients vis- iting their family doctors in Belgrade Health Centers. The results obtained for the studied group cannot be generalized to persons not using healthcare in Belgrade Health Centers or to individuals in other regions. The second limitation is the relatively small number of examined patients, especially those without hypertension due to the high prevalence of hypertension in the elderly. An additional limitation is the cross-sectional design and, as we have already underlined, such a study enabled us to find out only the prevalence of particular markers for CKD but not diagnosis and prevalence of CKD. Finally, kidney function was estimated by the creatininebased four-variable MDRD formula, as we had no opportunity for calibration of the serum creatinine assay to be traceable to IDMS. The MDRD formula overestimates GFR in older persons $[25,27]$ and therefore careful interpretation of the results is necessary. Thus, we considered all persons with detected kidney function abnormalities as persons with suspected CKD who need further examination.

In conclusion, in the group of 585 elderly persons, that consisted of 93 persons without hypertension and 492 with hypertension, a high prevalence of CKD markers was found. At least one marker for kidney disease was found in 46 (50\%) persons without hypertension and in 231 (47\%) with hypertension. The high prevalence of markers for CKD in symptomless elderly without hypertension indicated that the elderly, as a high-risk population, should be screened based on increased age alone. Further study in more diverse populations is needed before precise recommendations can be made.

\section{Acknowledgement}

This study was supported by a grant from the Ministry of Science and Technology of the Republic of Serbia (No. 175089).

\section{References}

1 Locatelli F, Vecchio LD, Pozzoni P: The importance of early detection of chronic kidney disease. Nephrol Dial Transplant 2002;17:2-7.

$\checkmark 2$ Ruggenenti P, Schieppati A, Remuzzi G: Progression, remission, regression of chronic renal diseases. Lancet 2001;357:1601-1608.

3 National Kidney Foundation: K/DOQI clinical practice guidelines for chronic kidney disease: evaluation, classification, and stratification. Am J Kidney Dis 2002;39(suppl 1):S1-S266.
4 National Institute of Diabetes and Digestive and Kidney Diseases, National Institutes of Health: USRDS 2007 Annual Data Report. Atlas of End-Stage Renal Disease in the United States, 2008

$\checkmark 5$ Coresh J, Selvin E, Stevens LA, et al: Prevalence of chronic kidney disease in the United States. JAMA 2007;298:2038-2047.
6 Wesson LG: Renal hemodynamics in physiological states; in Wesson LG (ed): Physiology of the Human Kidney. New York, Grune \& Stratton, 1969, pp 96-108.

7 Lindeman RD, Tobin J, Shock NW: Longitudinal studies on the rate of decline in renal function with age. J Am Geriatr Soc 1985;33: 278-285.

8 Zhou XJ, Rakheja D, Yu X, et al: The aging kidney. Kidney Int 2008;74:710-720. 
9 Chobanian AV, Bakris GL, Black HR, et al, National Heart, Lung, and Treatment of High Blood Pressure, National High Blood Pressure Education, and Program Coordinating Committee: The Seventh Report of the Joint National Committee on Prevention, Detection, Evaluation, and Treatment of High Blood Pressure: the JNC 7 report. JAMA 2003;289:2560-2572.

10 Anderson C: Proteinuria. Primer on Kidney Diseases, ed 2. New York, Academic Press, 1998, chapt 5 .

11 Mattix H, Hsu C-Y, Shaykevich S, Curhan G: Use of the albumin/creatinine ratio to detect microalbuminuria: implications of sex and race. J Am Soc Nephrol 2002;13:1034-1039.

12 Gansevoort RT, de Jong PE: Challenges for the present CKD classification system. Curr Opin Nephrol Hypertens 2010;19:308-314.

13 National Institute for Health and Clinical Excellence: Chronic kidney disease: early identification and management of chronic kidney disease in adults in primary and secondary care. NICE Clinical Guideline 73, 2008.

14 Takahashi S, Okada K, Yanai M: The Kidney Early Evaluation Program (KEEP) of Japan: results from the initial screening period. Kidney Int 2010;77(suppl 116):S17-S23.

15 Ford I, Bezlyak V, Stott D, et al: Reduced glomerular filtration rate and its association with clinical outcome in older patients at risk of vascular events: secondary analysis. PLoS Med 2009;6:e16.
16 Stevens LA, Li S, Wang C, et al: Prevalence of CKD and comorbid illness in elderly patients in the United States: results from the Kidney Early Evaluation Program (KEEP). Am J Kidney Dis 2010;55(suppl 2):S23-S33.

17 Go AS, Chertow GM, Fan D, et al: Chronic kidney disease and the risks of death, cardiovascular events, and hospitalization. N Engl J Med 2004;351:1296-1305.

18 Glassock RJ, Winearls C: An epidemic of chronic kidney disease: fact or fiction? Nephrol Dial Transplant 2008;23:1117-1121.

19 Roderick PJ, Atkins RJ, Smeeth L, Nitsch DM, Hubbard RB, Flectcher AE, Bulpitt CJ: Detecting chronic kidney disease in older people; what are the implications? Age Ageing 2008;37:179-186.

20 Levey AS, Eckardt KU, Tsukamoto Y, et al: Definition and classification of chronic kidney disease: a position statement from Kidney Disease: Improving Global Outcomes (KDIGO). Kidney Int 2005;67:2089-2100.

21 Hallan SI, Coresh J, Astor BC, et al: International comparison of the relationship of chronic kidney disease prevalence and ESRD risk. J Am Soc Nephrol 2006;17:2275-2284.
22 Chronic Kidney Disease Prognosis Consortium, Matsushita K, van der Velde M, Astor BC, Woodward M, Levey AS, de Jong PE, Coresh J, Gansevoort RT: Association of estimated glomerular filtration rate and albuminuria with all-cause and cardiovascular mortality in general population cohorts: a collaborative meta-analysis. Lancet 2010; 375:2073-2081.

23 Coresh J, Astor BC, Greene T, et al: Prevalence of chronic kidney disease and decreased kidney function in the adult US population: Third National Health and Nutrition Examination Survey. Am J Kidney Dis 2003;41:1-12.

24 Stevens PE, O’Donoghue DJ, de Lusignan S, et al: Chronic kidney disease management in the United Kingdom: NEOERICA project results. Kidney Int 2007;72:92-99.

25 Lin J, Knight EL, Hogan ML, Singh AK: A comparison of prediction equations for estimating glomerular filtration rate in adults without kidney disease. J Am Soc Nephrol 2003; 14:2573-2578.

26 Eriksen BO, Ingebretsen OC: The progression of chronic kidney disease: a 10-year population-based study of the effects of gender and age. Kidney Int 2006;69:375382.

27 Lamb EJ, Tomson CRV, Roderic PJ: Estimating kidney function in adults using formulae. Ann Clin Biochem 2005;42:321-334. 